\title{
FRAGMENTOS DE IDEIAS SOBRE ENSINO DE FILOSOFIA E RE-EXISTÊNCIA
}

\author{
Renata Lima Aspis ${ }^{1}$
}

RESUMO: o presente artigo, como já revela seu título, está constituído por notas esparsas, ou seja, não necessariamente atreladas por uma sintaxe de silogismos, premissas e conclusão, estando porém conectadas pelo interesse no ensino de filosofia. A primeira, ideias-flecha, trata da necessidade de um ensino de filosofia que se configure como experiência, que atravesse os estudantes como uma flecha, que os afete. A segunda nota, ideias-signo, é sobre o conceito deleuziano de aprendizagem, como decifração de signos. A terceira, ideiaspossível, trata da contraposição entre realização de possíveis e criação de possíveis. Segundo Deleuze, é necessário que os possíveis (e no nosso caso, no ensino de filosofia) sejam criados, eles não estão dados a priori. A quarta nota, ideiasafeto, trata de conectar o conceito de afeto spinozano com a possibilidade de um aprendizado que atravesse o corpo. E por fim o que poderia ser um ensino de filosofia como reexistência.

PALAVRAS-CHAVE: Ensino de Filosofia; Resistência; Deleuze; Afeto, Re-existência. 
ABSTRACT: The present article, as its title already reveals, consists of scattered notes, that is, not necessarily linked by a syntax of syllogisms, premises and conclusion, but connected by the interest in the teaching of philosophy. The first, arrowideas, deals with the need for a philosophy teaching that is configured as an experience, that goes through the students like an arrow that affects them. The second note, sign-ideas, is about the deleuzian concept of learning as sign deciphering. The third one, possible-ideas, deals with the contraposition between realization of possibles and creation of possibles. According to Deleuze, it is a necessity that the possibles (and in our case, it refers to the teaching of philosophy) are created, they are not given a priori. The fourth note, affection-ideas, tries to connect the Spinoza's concept of affection with the possibility of a learning that goes through the body. And finally, about what could be a teaching of philosophy as reexistence.

KEYWORDS: Philosophy Teaching; Resistance; Deleuze; Affection, Re-existence. 
A natureza joga o filósofo como uma flecha no meio dos homens, ela não visa, mas espera que a flecha venha a se cravar em algum ponto.

(NIETZSCHE)

\section{IDEIAS-FLECHA}

Depois da aula, no mestrado, ele veio até minha mesa e pediu para eu dar uma opinião sobre o andamento do seu projeto. Eu falei só umas poucas coisas e disse que não poderia avançar sem correr o risco de estar entrando no terreno do seu orientador e que isso não se pode fazer. Ele respondeu que sabia disso, que não se tratava disso, mas que era para eu falar, falar livremente, quase até me pediu para falar qualquer coisa. Eu fiquei olhando e ele completou: "É que eu gosto tanto das coisas que você fala, são tão inspiradoras. A sua última aula, sobre rizoma... aquilo mudou a minha vida! Eu fiquei pensando "Nossa... é isso mesmo...". Por que é que a gente não teve aquela aula com 15 anos?”. Seus olhos grandes, atrás dos óculos, me indagavam.

"Meu caro, nós tentamos, e você não imagina como! Tentamos bravamente afetar os alunos de 15 anos, no Ensino Médio, em nossas aulas de filosofia. Você não imagina como buscamos causar, no maior número de alunos que for possível, isso que você está sentindo agora”. Isto eu pensei naquele momento. E não se trata de um pensamento fortuito, mas de uma convicção permanente, muito clara.

$\mathrm{O}$ que ainda paira acima das cabeças, nesse universo da filosofia como disciplina obrigatória no currículo do Ensino 
Médio no Brasil, é, talvez, a renitente pergunta: para que aulas de filosofia na escola? Muita literatura sobre o ensino de filosofia foi criada desde o início da abertura política em meados da década dos anos oitenta até os dias atuais. Muito material didático/comercial foi produzido, na intenção de apoiar esse ensino, desde a volta da obrigatoriedade da disciplina, a partir da lei de 2008.

No entanto, ainda parece útil a pergunta sobre o para quê.

E poderíamos responder aqui, muito simplesmente, que o que o ensino de filosofia deseja é afetar os estudantes. Se alguns estudantes, ou muitos deles, a maioria, se sentissem, pelo menos uma vez, como o aluno do exemplo dado anteriormente, isso já poderia ser considerado um sucesso do curso de filosofia.

É inegável que o que cada professor de filosofia mais quer é que seus alunos gostem muito de suas aulas. Ora, mas isso todo professor deseja, seja qual for a matéria que ensine. Porém, em relação à filosofia, talvez ocorra que os professores, além disso, desejem que os estudantes amem a própria filosofia, que eles reconheçam a sua importância para suas vidas, que eles queiram se apossar das filosofias e seus modos de pensar, para usar em suas vidas. Do mesmo modo que ele mesmo, professor, o faz, ou tenta fazer.

No curso de filosofia, para além de ensinar modos de pensar das filosofias e conceitos filosóficos e as condições históricas da criação desses conceitos, para além do exercício racional de compreender a síntese conceitual que a filosofia 
faz e que confere sentido à experiência humana, para além disso tudo, a filosofia deve transpassar, atravessar o corpo, de um lado a outro, como uma flecha. Um curso de filosofia que não afeta os estudantes não vale de nada. Pois a filosofia diz respeito a, além de um modo de pensar, um modo de sentir e ainda a um modo de agir. Estar estarrecido diante das coisas e não poder deixar de fazer algo em relação a isso. Estar vivo e sentir e passar a viver de outro modo. A filosofia diz respeito ao homem pensante, mas, talvez, antes disso, ao homem desejante. Diz respeito àquele que não pode deixar de tentar pensar nas coisas que o tocam, incomodam, fazem mover-se, não se pode ficar quieto, àquele que não pode mais agir do mesmo modo, não pode deixar de fazer algo para efetuar no mundo aquilo que se lhe passa. É muito claro na história da filosofia o envolvimento dos filósofos com os problemas que os afligem, são muitos os exemplos, quase todos eles são exemplos, ou todos. Não se começa a desenvolver um tratado ou um ensaio filosófico por uma obrigação exterior a si mesmo. Trata-se de estar envolvido visceralmente com algo que incomoda, que faz pensar, um problema. O modo de pensar filosófico e sua criação, o conceito, vêm como tentativa de lidar com algo que se sente. O envolvimento do filósofo com a filosofia é visceral, é da esfera do sensível antes do que do inteligível. Filosofias são geradas por movimentos sensacionais. E se assim é, não há como pensar ensino de filosofia ausente das sensações, distante da afetação, das flechadas. "Os afectos atravessam o corpo como flechas, são armas de guerra" (DELEUZE; GUATTARI, 1997, p. 18). 


\section{IDEIAS-SIGNO}

O filósofo francês, contemporâneo, Gilles Deleuze, entende a aprendizagem como decifração de signos. Esta sua ideia está precedida de uma acusação que Deleuze faz à filosofia ocidental, ao longo de toda sua história, de que essa se baseia no pressuposto de que pensar é natural. Isto levaria à ideia de que aquele que não pensa, o faz por má vontade, ou seja, bastaria uma boa vontade para que se produzisse pensamento. (Aquele que está habituado ao trabalho escolar, sabe o quanto a acusação de falta de boa vontade nos jovens estudantes é recorrente. É bastante corriqueiro se ouvir reclamações por parte dos professores sobre a suposta falta de interesse dos alunos, a sua falta de vontade, falta de compromisso com o conhecimento, com os estudos). Se pensar não é natural, se para produzir pensamento não basta uma boa vontade, então como isto se dá?

Para Deleuze e Guattari, senso comum não é pensamento, as noções genéricas que se tem e que se usa de forma praticamente automática e esse fluxo de murmúrios que discursa por si mesmo dentro das cabeças, isto não é pensamento. Segundo esses dois pensadores, há três formas de pensamento: a arte, a ciência e a filosofia, que seriam três maneiras complementares entre si, sem qualquer hierarquia entre elas. Três formas de pensar, que significam três formas de "enfrentar o caos". A arte pensa "por sensações" e cria para si um "plano de composição", a ciência pensa "por funções" e traça um "plano de coordenadas" e a filosofia erige um "plano de imanência" em que possa pensar "por conceitos” (DELEUZE; GUATTARI, 1992). Arte, ciência e 
filosofia são as "caóides", filhas do caos, são formas de lidar com o caos, mantendo contato com ele, criam formas de possibilitar o pensamento, uma certa ordem.

O que é esse caos? É o fora, é aquilo que ainda não foi inventado, os possíveis que ainda não foram criados. Os possíveis têm de ser criados e isso quem faz é o pensamento, em contato com o caos, cada uma dessas formas de pensar, arte, ciência e filosofia, criam. Ora, mas o que seria essa criação de conceitos da filosofia? Se é verdade que não se pensa apenas apelando-se para uma boa vontade, o que seria, então, o que gera esse movimento de criação/pensamento? O problema. Algum problema, algo que incite o pensamento, algo que o obrigue. O pensamento surge por necessidade, "por arrombamento". É o problema que incomoda e que move o pensamento. O pensamento precisa ser provocado, deve haver um incômodo a ser transposto, uma estranheza insuportável que gere a necessidade de pensar: "[...] é absolutamente necessário que ele [o pensamento] nasça, por arrombamento, do fortuito do mundo. O que é primeiro no pensamento é o arrombamento, a violência, é o inimigo [...]" (DELEUZE, 2006, p. 203). O que provoca o pensamento é um signo que obriga a decifração, impele a criação, não se suporta ignorá-lo, é uma questão de vida, é uma questão visceral.

"Quem procura a verdade? [...] só procuramos a verdade quando estamos determinados a fazê-lo, em função de uma situação concreta, quando sofremos uma espécie de violência que nos leva a essa busca." (DELEUZE, 2003, p. 14). Quem procura a verdade é o ciumento diante dos signos da mentira do amado. É aquele que é feito faminto, 
obcecado, voraz, por meio da violência de algum signo. "O erro da filosofia é pressupor em nós uma boa vontade de pensar, um desejo, um amor natural pela verdade. A filosofia atinge apenas verdades abstratas que não comprometem, nem perturbam." (DELEUZE, 2003, p.15). Verdades abstratas. Não comprometem nem perturbam. Não se sai do lugar por elas, não afetam, não mudam as formas de sentir e de pensar, de crer, não fazem criar nada, nada de novo, de vivo. "Há sempre a violência de um signo que nos força a procurar, que nos rouba a paz. A verdade não é descoberta por afinidade, nem por boa vontade, ela se trai por signos involuntários." (DELEUZE, 2003, p.14-15). Esses signos são involuntários, por certo, se tromba com eles, são encontros. No caso de se pensar um ensino de filosofia, esses signos são involuntários para os alunos, mas não para os professores. O ensino, que é ação dos professores, este sim, pode ser planejado, planejado para ser acontecimento, isto é, para trombar com os alunos (como signos) e mudar algo em suas formas de sentir e de pensar.

Pensemos um ensino de filosofia como resistência, como aquele que não é adestramento do pensamento rumo à reprodução de verdades dadas, não é treino de assimilação de conteúdos objetivos e não pressupõe uma boa vontade. Não se pode contar com uma disposição natural para o pensar, mas apenas com "a contingência de um encontro que força a pensar, a fim de erguer e estabelecer a necessidade absoluta de um ato de pensar, de uma paixão de pensar" (DELEUZE, 2006, p. 203). Bem, está aí o que é interessante repetir: o involuntário, o fortuito, o contingente nesse encontro com o signo, o é para quem aprende e não para quem pretende ensinar. Sendo 
assim, perguntamos: como ensinar de forma intencional, planejada, cheia de táticas, já que estamos falando de um ensino de filosofia dentro da escola, porém criando ensejo para esse encontro com signos que provoquem o pensar no pensamento? Como ensinar de tal forma que os alunos sejam afetados por signos sem tentar imprimir algo neles? Como ser professor-vírus sem inocular com uma seringa? Pode-se tentar enxamear, ser vetor de signos, sementes ao vento, hélice, espraiar, voar, mover. Que signos são esses que é necessário irradiar por tudo, excessivamente, para que possam vir a afetar? Certamente não são conteúdos filosóficos: os textos, os métodos, a história, os conceitos, tudo isso vêm posteriormente, como consequência da busca, pois então já se estará tomado por essa busca, pela paixão de pensar. Um ensino re-existência possibilita aos alunos encontrar (serem encontrados, “tomarem um encontrão") com signos que os forcem a pensar. Estes signos estão em relação com as impossibilidades: a impossibilidade de pensar filosoficamente, a impossibilidade que obriga a inventar possíveis. É isto, é isto o que aquele que pretende ensinar poderá enxamear: impossibilidades. "Se um criador não é agarrado pelo pescoço por um conjunto de impossibilidades, não é um criador. Um criador é alguém que cria as suas próprias impossibilidades, e ao mesmo tempo cria um possível.” (DELEUZE, 1992, p. 167).

Como são esses encontros com signos? Encontrar as impossibilidades para criar, ser forçado a criar possíveis.

Aprender diz respeito essencialmente aos signos. Os signos são objeto de um aprendizado temporal, não de 
um saber abstrato. Aprender é, de início, considerar uma matéria, um objeto, um ser, como se emitissem signos a serem decifrados, interpretados. Não existe aprendiz que não seja "egiptólogo" de alguma coisa. [...] Tudo que nos ensina alguma coisa emite signos, todo ato de aprender é uma interpretação de signos ou de hieróglifos (DELEUZE, 2003, p. 4).

Trazer para a aula de filosofia signos indecifrados, hieróglifos, becos sem saída, as impossibilidades que forçam a criação de possíveis. Eis: dar o que pensar.

\section{IDEIAS-POSSÍVEL}

Para Deleuze, todo pensamento, todo devir, é involuntário. Para ele, a ideia de "mudar o mundo" por meio da realização de um projeto, uma utopia, uma revolução, entendida como a realização de um possível, é completamente inadequada. Pode-se dizer o mesmo de uma aula: não se pode pensar que deliberadamente se vai causar uma determinada mudança nas consciências a partir de um plano prévio. No lugar de revolução, Deleuze privilegia os devires revolucionários. A inversão operada pelo pensamento de Deleuze faz toda a diferença. Não se trata de realizar possíveis, mas de criar possíveis. Não se tem os possíveis previamente, não se tem antes de tê-los criados. "O que é possível é criar o possível." (ZOURABICHVILI, 2000, p. 335). Sendo assim, não se trata da disponibilidade atual de um projeto por realizar, mas de inventar. "O possível chega pelo acontecimento e não o inverso" (ZOURABICHVILI, 2000, p. 335), isto é, o 
acontecimento não é a realização de um dos possíveis do conjunto de possíveis que temos à disposição, à espera de realização, o acontecimento é uma abertura do possível, uma "emergência dinâmica de novo" (ZOURABICHVILI, 2000 , p. 337). Um “novo campo de possíveis" não é a mesma coisa do que "um novo campo de realizáveis", o possível que se realiza não é o mesmo que o possível que se cria. O que é possível é "criar novas possibilidades de vida" (ZOURABICHVILI, 2000, p. 338). E “[u]ma possibilidade de vida é sempre uma diferença" (ZOURABICHVILI, 2000, p. 338), pois essas "novas possibilidades de vida" são novas formas de sentir, novos modos de relação com aquilo que é o intolerável.

Essa criação de novas possibilidades de vida supõe novas maneiras de afetar e ser afetado, uma "distribuição diferencial dos afetos" (ZOURABICHVILI, 2000, p. 339). Esse tipo de transformação nas subjetividades não é deliberado, voluntário, não se escolhe, ele acontece, acontece por encontros. O que se pode escolher é assumir as consequências dessa mutação ou fingir que nada aconteceu, como aponta Zourabichvili. O que permite essa mutação é o encontro, o encontro com o fora, o encontro com o impensado, com aquilo que torna uma eventualidade qualquer em algo que afeta. Por isso o "possível não preexiste, ele é criado pelo acontecimento. É uma questão de vida. O acontecimento cria uma nova existência, ele produz uma nova subjetividade (novas relações com o corpo, o tempo, a sexualidade, o meio, a cultura,otrabalho...)"2 (DELEUZE; GUATTARI, 2007, s/p apud ZOURABICHVILI, 2000, p. 343-4). Novas relações. Trata-se, pois, não de uma tomada de consciência, mas de uma nova sensibilidade, se é 
atravessado por outras formas de sentir e de perceber, “[...] já não se suporta o que se suportava antes, ainda ontem; a repartição dos desejos mudou em nós, as nossas relações de velocidade e de lentidão modificaram-se, assalta-nos um novo tipo de angústia, mas também uma nova serenidade. Os fluxos mudaram [...]" (DELEUZE; PARNET, 2004, p. 153). Novas relações e novos fluxos. As subjetividades são atravessadas e já não são mais as mesmas, já não percebem e sentem e pensam como antes. Isso se dá por meio de encontros. Encontro com aquilo que nos força a pensar, com o que nos faz sentir e perceber de outra maneira, o encontro com o fora, com o impensável.

[A] busca da verdade é a aventura própria do involuntário. Sem algo que force a pensar, sem algo que violente o pensamento, este nada significa. Mais importante do que o pensamento é o que "dá que pensar"; mais importante do que o filósofo é o poeta [...] o poeta aprende que o essencial está fora do pensamento, naquilo que força a pensar. O leitmotiv do Tempo redescoberto é a palavra forçar: impressões que nos forçam a olhar, encontros que nos forçam a interpretar, expressões que nos forçam a pensar (DELEUZE, 2003, p. 89).

Encontros que forçam a pensar, que forçam a olhar, a interpretar. Assim um ensino re-existência, um ensino acontecimento. Quando se funda em uma imagem do pensamento pré-concebida, priva-se o pensamento de sua necessidade, e, portanto, nada é forçado, nada é criado. Repetimos: verdades abstratas não comprometem nem 
perturbam. Não se sai do lugar por elas, não afetam, não mudam as formas de sentir e de pensar, de crer, não fazem criar nada, nada de novo, de vivo. Por outro lado, quando não se funda o pensamento e, ao invés, se força a pensar, tudo é possível. Tudo é possível quer dizer que o campo de criação está aberto e, portanto, tudo está por fazer. É nesse sentido que um ensino re-existência não é a realização de um plano, mas o enxameamento de signos que forcem novas formas de pensar, novas formas de sentir e perceber.

\section{IDEIAS-AFETO}

Arriscamos: dar o que pensar passa antes pelo corpo, não é uma questão intelectual, mas uma questão de vida e vida é corpo, vida pulsa, é quente, flui. Aqui se explica resistência como re-existência: insistência em existir, reincidência na existência. A cada captura da vida, a cada assalto à vida, a cada tentativa de coisificação, de massificação, de assujeitamento e distração de si, trata-se de insistir em existir, de novo e de novo. Portanto re-existência é um movimento, reiterado em passos e piruetas, criação de caminhos e retomadas, resistentemente, re-existentemente. E o que seria a existência? Existir como um humano? Os processos pelos quais um indivíduo vai passando e vai se subjetivando são processos simbólicos sim, tecidos pela linguagem e substanciados em significados, de si, dos outros, do mundo e de tudo que está implicado nessas relações. No entanto, antes de mais nada são processos que se dão no corpo. O que passa pelas experiências, o que sente, o que pode se afetar é 
o corpo. As experimentações são possíveis através do corpo. “[...] o corpo, por si só, em virtude exclusivamente das leis da natureza, é capaz de muitas coisas que surpreendem a sua própria mente" (SPINOZA, 2011, p.101). "O que pode o corpo?" é uma pergunta que Deleuze elabora a partir da ideias de Spinoza, que afirmou:

O fato é que ninguém determinou, até agora, o que pode o corpo, isto é, a experiência a ninguém ensinou, até agora, o que o corpo - exclusivamente pelas leis da natureza enquanto considerada apenas corporalmente, sem que seja determinado pela mente - pode e o que não pode fazer (SPINOZA, 2011, p.101).

O existir tem relação com os afetos e as ideias. Verifiquemos isto.

Para Spinoza, os afetos são todos os modos de pensamento que não representam nada, não são representativos. Por exemplo, quando alguém deseja alguma coisa, deseja um objeto e sobre esse objeto pode-se ter uma representação, uma ideia. No entanto sobre o próprio desejo, o ato de estar desejando aquilo, não há representação, não é uma ideia, esse modo de pensamento não representativo é o afeto. Ideia e afeto são duas espécies de modo de pensamento que têm naturezas distintas, mas um não se reduz ao outro, não há uma hierarquia, um valor maior de um sobre o outro. $\mathrm{O}$ que se pode dizer é que todo afeto é antecedido por uma ideia pois quando se deseja, se ama, teme, tem aversão etc., é sempre sobre a ideia de uma coisa, por mais confusa e indefinida que seja, há que se ter uma ideia antes do afeto. 
As ideias são representações de coisas e isto é sua realidade objetiva. No entanto, além desta, que é sua realidade extrínseca, a ideia tem também uma realidade intrínseca, formal. Quer dizer, a ideia é ela também algo, independentemente do objeto que ela representa e dessa relação de representação que tem com o objeto. A sua realidade formal, intrínseca, faz com que a ideia seja ela própria uma coisa. A realidade formal da ideia é o que é afirmado por Spinoza como um certo grau de realidade ou de perfeição que toda ideia possui. Por exemplo, a ideia de Deus tem um grau de realidade ou de perfeição imensamente maior do que a ideia de cachorro, que é uma coisa finita. A realidade objetiva da ideia, isto é, a relação que ela tem com aquilo que ela representa e a realidade formal da ideia podem estar muito ligadas entre si, em alguns casos, mas nunca são a mesma coisa. Repetindo: toda ideia possui essas duas distintas dimensões, a realidade objetiva que é a relação com a coisa que ela representa e a realidade formal, que é um certo grau de realidade ou de perfeição, que a constitui como uma coisa, uma ideia enquanto tal.

Tudo isso pode parecer bastante complicado, mas é linda e até simples a relação que Spinoza faz entre existir e ideias e afetos. Vejamos, o existir, para Spinoza, é um contínuo de ideias que se sucedem em nós. E "de acordo com essa sucessão de idéias, nossa potência de agir ou nossa força de existir é aumentada ou é diminuída de uma maneira contínua, sobre uma linha contínua, e é isso que nós chamamos afeto [affectus], é isso que nós chamamos existir" (DELEUZE, 1978 , s/p). O afeto é aquilo que Deleuze gosta de chamar de variação, uma variação constante da força de existir de alguém, que pode ser mais alegre, quando a força de existir e a potência de agir aumentam, e triste quando diminuem. 
Desliza-se continuamente entre o aumento e a diminuição da força de existir, da potência de agir, conforme as ideias que vão se sucedendo em nós. Perceba que não se trata de alguém, "ter" uma ideia, mas as ideias vão se sucedendo nas pessoas, as ideias vão se sucedendo nos corpos. Spinoza demonstra geometricamente em Ética como se dá nossa vida: por meio de ideias que se sucedem continuamente, e elas se sucedem conforme os corpos vão se encontrando com as ideias. " $[\mathrm{O}]$ afeto é constituído pela transição vivida ou pela passagem vivida de um grau de perfeição a outro, na medida em que essa passagem é determinada pelas idéias; porém em si mesmo ele não consiste em uma idéia, ele constitui o afeto" (DELEUZE, 1978, s/p).

Quando encontro alguém de quem gosto, fico alegre, vejo José, por exemplo, se aproximando, atravessando a rua para vir falar comigo, a ideia de José se dá em mim. Essa ideia, em relação a mim, tem um certo grau de realidade ou de perfeição. A ideia de José tem mais perfeição intrínseca do que a ideia da reunião para a qual estou me encaminhando no momento que vejo José. Isto porque a ideia de José me alegra e a ideia da reunião me entristece. Uma aumenta minha potência de agir, aumenta minha força de vida e a outra a diminui. Vou para a reunião e vejo que serão servidos pãezinhos doces que me lembram da minha infância feliz, chega um colega do qual não gosto, olho pela janela e vejo pássaros no céu, sinto um perfume forte e excessivo da colega ao lado, alguém gagueja nervoso, etc. etc. etc. A nossa existência se dá por uma sucessão constante de ideias que se dão em nós. Há uma variação contínua conforme a realidade intrínseca de cada uma dessas ideias é mais ou menos perfeita em relação a nós. 
Segundo Spinoza, nós somos fabricados como autômatos espirituais. Enquanto autômatos espirituais, há o tempo todo idéias que se sucedem em nós, e de acordo com essa sucessão de idéias, nossa potência de agir ou nossa força de existir é aumentada ou é diminuída de uma maneira contínua, sobre uma linha contínua, e é isso que nós chamamos afeto [affectus], é isso que nós chamamos existir (DELEUZE, 1978, s/p)

A filosofia de Spinoza, em sua "Ética", vai ficando mais complexa e mais profunda conforme se avança. Não cabe aqui a exploração de mais do que já tratamos até este ponto, a não ser apenas afirmar que a potência de ação, a força de vida de um corpo, aumenta ou diminui, podendo chegar até a morte (decomposição), nos encontros bons ou maus com outros corpos que são nocivos ou benéficos à composição desse corpo. Quando tomo uma água fresca e limpa em um dia de calor ou quando tomo uma água envenenada, por exemplo. Sendo assim, é possível afirmar que um corpo pode ser definido pelo conjunto das relações que o compõe ou, em outras palavras, pelo seu poder de ser afetado. Portanto, à pergunta: o que pode um corpo? A resposta: ser afetado. E para estar de posse da sabedoria é necessário que se ultrapasse a apreensão que se faz de um corpo por meio do acaso dos encontros. É necessário saber qual é o poder de um corpo com relação a ser afetado.

\section{ENSINO DE FILOSOFIA RE-EXISTÊNCIA}

O que pode um estudante? Ser afetado. O que resta ao professor? Signos. Enxamear por toda parte. Signos 
indecifrados que provoquem o pensamento, incomodem e forcem ao movimento da busca. Como fazer isso? Temos de inventar. Signos que gerem bons afetos. Novamente: "Os afectos atravessam o corpo como flechas, são armas de guerra” (DELEUZE; GUATTARI, 1997, p. 18). Qual é a "guerra", a guerrilha do ensino de filosofia como reexistência? Aumentar a potência de ação dos estudantes, aumentar sua força de vida, gerar alegria. Spinoza, atento à dimensão política chama a atenção para o fato de as pessoas que detêm o poder precisarem afetar os outros de maneira triste. Para o exercício do poder, seja em que dimensão for, é necessário que se afete os outros de forma a diminuir sua potência de agir. "Spinoza diz, no 'Tratado teológico-político', que esse é o laço profundo entre o déspota e o sacerdote: eles têm necessidade da tristeza de seus súditos" (DELEUZE, 1978, s/p). A tristeza spinozana é a diminuição da força de vida, da potência de agir, e, ao contrário, a alegria é o aumento da força de vida, da potência de agir. Sendo assim, inversamente ao déspota e ao sacerdote, o professor deseja afetar os estudantes de uma maneira alegre. É desejável que a ação de um ensino de filosofia como re-existência potencialize a vida. $\mathrm{Na}$ alegria se aprende, na alegria podese acreditar no mundo, é possível criar, criar outros mundos, criar novas possibilidades de vida. Essa guerrilha é travada no micro, cada aula, cada avaliação, cada texto, cada tática pedagógica, cada conceito: micropolítica de um ensino de filosofia possível. Tem de ser inventado, renovadamente, insistentemente, re-existir. 


\section{NOTAS}

${ }^{1}$ Professora de filosofia da Faculdade de Educação da Universidade Federal de Minas Gerais - UFMG. Doutora em Educação pela Universidade Estadual de Campinas (UNICAMP). E-mail: renaspis@terra.com.br.

${ }^{2}$ Tradução para o português Maria Cristina Franco Ferraz. No original leiase: "Le possible ne préexiste pas, il est créé par l'événement. C'est une question de vie. Lévénement crée une nouvelle existence, il produit une nouvelle subjectivité (nouveau rapports avec le corps, le temps de la sexualité, le milieu, la culture, le travail...)" (DELEUZE; GUATTARI, 2007, s/p). Disponível em: <http://www.revue-chimeres.fr/drupal_chimeres/?q=node/87> Aceso em: 7 setembro 2016 .

\section{REFERÊNCIAS}

DELEUZE, G. Conversações, 1972-1990. Tradução Peter Pál Pelbart. Rio de Janeiro: Editora 34, 1992.

DELEUZE, G. Proust e os signos. Tradução Antonio Carlos Piquet e Roberto Machado. 2. ed. Rio de Janeiro: Forense Universitária, 2003.

DELEUZE, G. Diferença e repetição. Tradução Roberto Machado e Luís B. L. Orlandi. São Paulo: Graal, 2006.

DELEUZE, G. DELEUZE / SPINOZA. Cours Vincennes 24/01/1978. Aula sobre ideia e afeto. Tradução Francisco Traverso Fuchs. Disponível em: <http://www.webdeleuze. $\mathrm{com} / \mathrm{php} /$ texte $\cdot \mathrm{php}$ ? cle $=194 \&$ groupe $=$ Spinoza\&langue $=5>$. Acesso em: 23/09/2016. 
DELEUZE, G.; GUATTARI, F. O que é a filosofia? Tradução Bento Prado Jr. e Alberto Alonzo Muñoz. Rio de Janeiro: Editora 34, 1992.

DeleuZE, G.; GUATTARI, F. Mil Platôs: capitalismo e esquizofrenia, v. 5. Tradução Peter Pál Pelbart e Janice Caiafa. São Paulo: Editora 34, 1997.

DELEUZE, G.; PARNET, C. Diálogos. Tradução Eloisa Araújo Ribeiro. Lisboa: Relógio D’Água, 2004.

SPINOZA B. Ética. Tradução Tomaz Tadeu. 2. ed. Belo Horizonte: Autêntica Editora, 2011.

ZOURABICHVILI, F. "Deleuze e o Possível (sobre o involuntarismo na política)". Tradução Maria Cristina Franco Ferraz. In: ALLIEZ, É. (Org.). Gilles Deleuze: uma vida filosófica. Coordenação da tradução Ana Lúcia de Oliveira. São Paulo: Editora 34, 2000.

ZOURABICHVILI, F. O vocabulário de Deleuze. Tradução André Telles. Rio de Janeiro: Relume Dumará, 2004. 